\title{
Historic Community Preservation: The Approach Suitable to Thai Context
}

\author{
Supoj Prompayuk ${ }^{1} \&$ Panayu Chairatananonda ${ }^{1}$ \\ ${ }^{1}$ Faculty of Architecture, King Mongkut's Institute of Technology Ladkrabang (KMITL), Bangkok, Thailand \\ Correspondence: Supoj Prompayuk, Faculty of Architecture, King Mongkut's Institute of Technology \\ Ladkrabang (KMITL), Bangkok, Thailand. Tel: 661-250-8280. E-mail: supojter@gmail.com
}

Received: September 18, 2017

Accepted: October 2, $2017 \quad$ Online Published: October 28, 2017

doi:10.5539/ass.v13n11p120

URL: https://doi.org/10.5539/ass.v13n11p120

\begin{abstract}
Historic community is actually a kind of cultural heritages. However, in Thailand, a phenomenon contradicting such idea is often found. Namely, tangible heritages, such as residences, buildings or architectural features are well preserved, while intangible heritages, such as social, economic and cultural structure and traditional way of life are widely changed as a result of rising economic opportunities. This phenomenon emerges after a community becomes a historic community which is a way to raise the economic values in locality. Consequently, the other values of the historic community are diminished or faded away. However, there are Thai communities which can preserve the original conditions and maintain their value as a historic community. Hence, this research aims to find the preservation approach and supporting factors in those communities. It is found that those communities raise awareness of local inhabitants and attract them to participate in the preservation in the direction which they want the community to be. As a result, this preservation becomes more sustainable.
\end{abstract}

Keywords: historic community, cultural heritage, architectural preservation, preservation approach

\section{Introduction}

\subsection{Historic Community Preservation}

According to the United Nations Educational, Scientific and Cultural Organization (UNESCO), cultural heritages comprise creativities of the preceding generations. They can be tangible heritages, such as buildings, and intangible heritages such as local culture (United Nations, 2012). Therefore, the cultural heritages include more than ancient monuments or buildings. They include the whole surroundings and ecological system which demonstrate the activities and success of the preceding generations. They are a kind of important global resources which cannot be reproduced (Feilden \& Jokileht, 1998). Hence, any cultural preservation effort should not be limited to physical preservation of architectural features and nature. The cultural heritage preservation should expand to way of life, art, languages, traditions and customs.

The historical community preservation is a social phenomenon which can be found more often recently due to many benefits other than psychological benefits, for example beauty and uniqueness of town community, history, and cultures of people in the community. The historical community preservation is widely accepted for its social and economic benefits for the town community (Lapenas, 2002). The preservation starts from town revitalization. It creates the community activities, job creation and communal revenues. It can help retain small businesses and enterprises by attracting the public attention. The building repair and conservation saves the budget and taxes, in comparison with construction of new buildings. Moreover, it solves the problem of inadequate residences in the town community, as the preservation maintains the housing stock in the middle of the town. Lastly, the historic community preservation prevents the town sprawl, because the preservation enables the original area to further support activities of the town. When the town does not spread too quickly, fewer resources are consumed, as there is no need to spend these resources for infrastructure construction in the newly-expanding town area.

Hence, the historic community is actually a kind of cultural heritages. However, in Thailand, a phenomenon contradicting such ideas is often found. Namely, tangible heritages, such as residences, buildings or architectural features are well preserved, while intangible heritages, such as social, economic and cultural structure and traditional way of life are widely changed as a result of rising economic opportunities. This phenomenon emerges after a community becomes a historic community which is a way to raise the economic values in 
locality. Consequently, the other values of the historic community are diminished or faded away. Anyhow, in foreign countries, such as the U.S.A., the U.K. and Japan, (Pimolsathien, 2013) there are case studies of relatively successful preservation process.

\subsection{Condition of historic community preservation in Thailand}

Currently in Thailand, the cultural and historic community preservation focuses on the buildings, premises and surrounding physical environment which generates expenditures higher than the capacity of the local community.

One of fund raising methods for preservation is to promote and support the communities with cultural and historic values to become a tourist site. Some facilities are added to the communities to promote the tourism, for example hotels, restaurants and tourist information service. This transformation aims to raise fund from tourism activities to physically preserve the communities.

However, following such preservation processes, it is found that the communities have better economic opportunities to gain more tourism revenues. Such condition attracts outsiders to seek incomes from the tourism potential in the local. Moreover, it drives away the old inhabitants in the area. The investors buy the land from the locals to construct a hotel for tourists. And the land owners are happy to sell the land, as they receive a pleasant offer.

The consequence is the relocation of original inhabitants out of the area. As a result, the original charm and uniqueness, such as way of life, social and economic conditions and cultures, which contribute to the community's value diminishes and fades away. Eventually, the communities lose their cultural and historic values.

For instance, Amphawa floating market community is a famous market which attracts a large number of Thai and foreign tourists. Based on the previous research, it was found that the large number of tourists coming to the community tremendously changes the economic, social and cultural conditions of the community (Prompayuk \& Chairatananonda, 2017). The price of the land rises quickly. Most locals do not mind selling their real estate which is ancient wooden houses on the river's bank which actually contain very high values in the perspective of conservers and outsiders. The investors demolish these ancient houses to construct the western styled hotels which contradict the surrounding landscape. On the other hand, it is undeniable that the land which is worth many million Baht brings about the better life and more revenues for the locals. Additionally, the rent becomes so high that some locals cannot bear such economic burdens. Therefore, they have to leave the area to pursue other occupation. Some of them buy a house of a land developing project instead of living on the river's bank as usual. Consequently, the original inhabitants are replaced by vendors from outside. As for the culture and society, the farmers become vendors and tourism service providers. The old culture is presented merely to respond the tourists' demand. The good side is it conserves the original customs, such as alms offering on the boats. However, the social behaviors may also change due to the changing social context (Prompayuk \& Chairatananonda, 2017).

Another example is Chiang Khan which is also famous for its cultural heritage. However, it is affected less than the Amphawa. Although many investors have bought many plots of land, and the locals enter into tourism economic sector, the occurring change does not greatly replace the long existing culture. The locals slightly move out from Chiang Khan.Thanks to the area administration and legal provision, the change gradually emerges. The areas surrounding Chiang Khan are still rural. In the same time, it is undeniable that tourism transforms Chiang Khan to be a town society. Aside from physical change, the locals dress up more fashionable, drink and eat like tourists and adopt the central Thai language instead of speaking their local language (Prompayuk \& Chairatananonda, 2017).

\subsection{Preservation approach in foreign countries}

The U.S.A, the U.K. and Japan have long developed the preservation approach of historic town and community. They attain success in terms of town preservation and become a model of other countries (Chukaew, 2014). In particular, the U.K. is not only a model of democracy. It is a model for town preservation as well (Tonubol, 2013).

In most cases, the successful historic community preservation abroad starts from the local initiative, afterwards, the governments realize the significance of historic community preservation and legislate the law to allow the local administrations to declare their historic areas. In the same time, the governments also increase the economic stimulus. (Pimolsathein, 2012)

The successful historic community preservation abroad does not cover only the preservation. It also allows the towns to be another efficient economic drive. In Japan and Western Europe, the governments change the towns 
to be an effective tool for economic competition, with emphasis on sustainable economy (Sudchaya, 2009). These countries have advanced in terms of laws and preservation process. They raise awareness and create innovations for architectural preservation (Tonubol, 2013). The governments have improved the preservation laws which separate the historic area from ancient monuments. They decentralize the administration authority and allocate the budget for preservation and organization establishment to allow the local inhabitants and local administrations to manage the preservation of their own cultural heritages. (Chukaew, 2014) Many states in the U.S.A. grant the power to the public to establish an area in their village, community or town as a historic site, by which the federal government authorizes the local governments with regard to preservation (Sukolratanametee, 2009). As for the interfering measures, the federal government pursues both intensive and mandatory measures. (Pimolsathien, 2013)

In the U.K., the heritage tax is exempted, and VAT is exempted or deducted in exchange for old building preservation under the prescribed regulations and conditions (Pimolsathein, 2012). In the U.S.A., the preservation right prescribed by the local administration under the zoning regulation, together with some of preserved buildings, is transferred to a preservation organization (preservation easement) to lessen the burden of real estate tax. The stimulus is different in each state of the country (Pimolsathein, 2012). As for Japan, the government pursues the historic community preservation integration between town planning and preservation. Many prefectures support the community participation (Machizukuri), together with the tax incentive for building preservation (Pimolsathein, 2012).

Based on the literature review with regard to case studies of historic community preservation abroad such as the U.S.A, the U.K. and Japan, the researcher concluded the variables to serve as the research tools. These variables include establishment of governmental agencies, establishment of private agencies, legal measures, local authority, public participation, tax measure, financial support and tourism measure. As for case studies in Thailand, from the concept of both tangible and intangible heritage preservation (United Nations, 2012), the researcher selected a number of communities with the following criteria; the community has managed the preservation in the locality for some time. There is a local group working under the purpose of community preservation. The preservation activities have been continuously carried out and such preservation activities can conserve physical buildings and environment at the certain level. Some outstanding features of buildings and environment still exist. Original inhabitants in the community preserve their unique way of life and culture.

\section{Method}

The main standpoint of this research is the principle that the successful historic community preservation must preserve both concrete, tangible and physical objects and abstract, intangible things. This research aims to study the preservation approach. The researcher conducted a field survey and interview to collect the opinions of interested persons. The methodology is in line with the phenomenology research paradigm. It is a methodology used in social science for qualitative research.

\subsection{Research Design}

Phenomenology is the explanation of occurring phenomenon. It is the study via direct exposure to the context (i.e. studied area/community). Such context is defined by interpretation. The phenomenologist abandons the learned concepts to open to the beliefs, rationale and definitions of the information providing persons or groups to explain their feelings, thoughts and behaviors. (Sahachaiseri, 2005) The phenomenologist tends to adopt the methodology of qualitative research, as it emphasizes on the information of feelings, visions, meanings and cultures. It focuses on direct exposure to information and phenomenon. It is less likely to use statistics for analysis. The phenomenologist tends to create a new hypothesis and conclusion rather than proving the existing hypothesis. (Chantavanich, 2016) According to social science, an object of studying is called a social phenomenon. The social phenomenon has outstanding characteristics different from natural phenomenon. It has meaning, complication, uncertain movement and interconnection. Phenomenology describes the incident or object of study with rationale of researcher, relying less on affirming figures or statistics. (Sahachaiseri, 2005)

The objective of qualitative research is to conduct a holistic study and describe the overall phenomenon (inclusive and integrated) under the studied context. (Miles \& Huberman, 1994) The study is conducted with various viewpoints to understand and translate the meaning of such particular context. It analyzes the nature of existing objects (Groat \& Wang, 2002) to explain and interpret the phenomenon through synthesis of numerous variables (Denzin \& Lincoln, 1998). It is a kind of interdisciplinary which studies the phenomenon under its natural and true context. The field research is conducted without control and laboratory experiment. It emphasizes the variables of feelings, thoughts and mind.

This research adopts descriptive analytic induction to study the community or particular case to initially illustrate 
the overall picture. The researcher of qualitative research describes details of general environment of the community or case study through narration of general information such as geography or location. Regarding the main analysis method, the researcher of qualitative research interprets the phenomenon to reach the inductive conclusion. This method uses numerous minor concrete information to form an abstract conclusion based on their commonly-found characteristics. The qualitative research tends to use analytic induction rather than utilization of statistics (Chantavanich, 2016).

\subsection{Selection of Study Areas}

The researcher of qualitative research selects the areas of study based on 6 principles (Chantavanich, 2016). (1) The locals can answer the research questions. (2) Each area has different contexts. (3) The area size is suitable to the study period. (4) The occurring phenomena in communities are different. (5) Easy access to information and. (6) convenience in area access. As for the selection of Thai historical communities, from the concept of sustainable heritage preservation (United Nations, 2012), the selection criteria are the followings; the community has managed the preservation in the locality for some time. There is a local group working under the purpose of community preservation. The preservation activities have been continuously carried out. Such preservation activities can conserve buildings and physical environment to the extent that some outstanding features of buildings and environment still exist. Original inhabitants in the community preserve their unique way of life and culture.

\subsection{Research Procedures}

To systematically conduct the research, portray the direction and scope of research and avoid any mistake which could possibly be disadvantage of the research, it is necessary to plan the research. The research is divided into 6 steps, as follows;

Step 1: Conduct the literature review and study the documents related to abroad successful cultural heritages preservation concepts and methods. Through this process, the researcher will learn the methods, operational methods, preserved object and working agencies, and then create the research variables.

Step 2: Study the effect on communities in Thailand through reference document and field survey to learn the occurring effect through the documents and perspective of local inhabitants.

Step 3: Create the research tool such as interview questions based on variables concluded from the foreign literature review of cultural heritage preservation approach. The researcher adopts the successful preservation to be a tool when conducting an interview with concerned persons.

Step 4: Conduct the in-depth interview with interested persons, academics and architects in Thai historic communities to find a preservation approach suitable to Thai context.

Step 5: Conduct the in-depth interview with experts to analyze information.

Step 6: Analyze the interview result with qualitative methodology

\subsection{Research Tools}

The researcher conducted structured and unstructured interview, since they have different advantages and disadvantages. With both types of interviews, the researcher can collect complete information which wholly covers the contents. The interview is a research tool broadly used in the field of social science. It is the interaction between the interviewer and interviewee to collect information. Namely, it is a conversation with a specific purpose. The flexible tool allows additional explanation and investigation through conversation. The interviewer and interviewee can inquire and observe each other (Chantavanich, 2016). On the contrary, its disadvantage is that the researcher can collect information from a small sample group, in comparison with questionnaires. However, this research is the study under the real context. Hence, the researcher wants the information from the locals and opinions from interested persons in the area. The interview serves as a proper tool to access data, opinion and in-depth information.

The open-ended questions of structured interview prepared in advance according to points and variables gained from case studies of abroad historic community preservation. It is the interview with fixed questions and specifications. The researcher determines the process and edits questions to be a guide in interviewing. Since the questions are open-ended, the interviewee can give whatever answers. (Supang Chantavanich, 2016) It is a proper tool for this research, since the researcher wants the clear opinions according to the points concluded from case studies of abroad historic community preservation.

The unstructured interview is a broad conversation with the locals and interested persons to gain the opinions outside the points of the structured interview. The researcher believes that the social phenomenon found in 
various Thai historic communities is different from case studies of abroad historic community preservation. The unofficial conversation may raise additional points. The unstructured interview is suitable to reveal unknown information, as the researcher can see the overall picture and understand cultural phenomenon. The researcher loosely prepared some general questions in advance. Its disadvantage is that the unstructured interview may go out of control. If the interviewee loses the track, the interviewer may face difficulties in information analysis (Supang Chantavanich, 2016: 76).

The unstructured interview contains the in-depth interview. The interviewer had the points of interest attained from the previous interviews. Then, the interviewer tries to survey deeper in these points, as the interviewer already knew what information of which points should be gained. (Supang Chantavanich, 2016:77) During the field work, the researcher determined the sample group for the interview which was local academics, inhabitants, entrepreneurs, governmental officials and interested persons. The in-depth interview was expected to cover opinions of the locals from all aspects.

\subsection{Research Data Analysis}

In the information analysis process, the researcher adopted the qualitative research methodology which is analytic induction. Analytic induction is interpretation to reach conclusion based on concrete information and visible phenomenon. (Supang Chantavanich, 2016:144) The analysis process is, as follows; (1) Typology and Taxonomy, by which the researcher separated the points of abroad historic community preservation for each studied area. Then, the researcher conducted the constant comparison, i.e. the comparison of information attained from each studied area to find convergence and divergence of the happening. Later, the researcher analyzed the content which is the analysis of all attained information through description and explanation of the occurring phenomenon. (Creswell, 2013)

With regard to information comparison, the researcher set the points and variables from the successful preservation methods in foreign countries. Initially, the researcher made minor conclusions after comparison of information types and characteristics to determine their interrelationship. The results were compared with the case studies in Thailand. When the information was compared to each other, the occurring phenomenon was abstract. The researcher created the table of interrelationship/incoherence. The comparison revealed the interrelationship which emerged through the reoccurrence, relationship format and similar characteristics. (Supang Chantavanich, 2016:137) The expanded comparison helped the researcher to see the main points and understand the phenomenon. The researcher selected only important points and made in-depth analysis to find the conclusions. The conclusions which are abstract paradigm are the first step leading to bigger abstract conclusions.

The last step is content analysis or analysis of information attained from the structure and unstructured interviews with involved persons and interested persons in the area. In social science, the content analysis plays a vital role in describing or classifying the studied content. The key factors in content analysis are information systematization, classification, inclusion and consistency of interviewees' answers with research questions (Supang Chantavanich, 2016:144). To ensure that the research is carried out according to the process and covers the important points, the researcher planned the questions of structured and unstructured interviews and in-depth interview to ensure the completeness of information for further analyses.

\section{Results}

\subsection{Sam Chuk Market Community}

Initially, the preservation activities were driven through the economic and academic working committee which comprised academics, and representatives from educational institutions and outside organizations. The working committee functioned like a mentor encouraging and supporting a community movement. It allocated the budget for physical, social and management improvement. (Saepoo, et al., 2007) During 2003-2006, Chumchonthai Foundation assigned Sam Chuk Market Community as 1 of 12 pilot towns for living, on the condition that the local community had to participate in the town improvement. As a result, the locals discussed for the change of their community. (Seublah, 2013)

The success of the preservation of 100 -year-old Sam Chuk Market Community results from the mutual participation of the locals and governmental agencies which directly and indirectly affects the community. They bring back their past which was once defined by the government as "area with no economic value." The process revitalizes the community and brings about the business opportunity. (Kamolsakdavikul, 2013) In Sam Chuk, the locals serve as a center of decision making regarding the preservation. The locals define the preservation, assess the historical values, and translate the preservation plan into action. Therefore, the community has the central 
role in the preservation approach (Saepoo et al., 2007).

From this research's in-depth interview, the advantage of Sam Chuk is the main road passing through the community. The convenient transportation facilitates the visit of outsiders. The outsiders come and realize the value of old buildings in Sam Chuk Market Community. Thanks to more tourists, the community can sell more local products. Moreover, the publicity by the local preservation agencies attracts more tourists. The locals agree that they can earn more revenues from tourism for the community. More new products are offered to support the tourism. The locals adjust the landscape and clean up the place. They invite the public organizations and academics to mutually draft a development plan for sustainable tourism, environment and quality of life. The community does not wait for the governmental operation and their operation becomes concrete and yields good result.

Then, Sam Chuk Community establishes the local committee to oversee and manage the physical objects in the community. However, the committee does not have legal authority. Their issued measures can only ask for the local participation. All committee members are local inhabitants in Sam Chuk, which makes it easy to gain the local cooperation. The Sam Chuk Community Committee holds the local meeting to mutually decide the operation. They allocate a platform (Lan Pho) for local activities. They attract the new generation to work for the community. The public and academics help on the community management. According to the field work, only $20 \%$ of Sam Chuk inhabitants are the outsiders. This figure contributes to the community strength. Most operations of committee enjoy the local cooperation. In Sam Chuk, there is local announcement closely and thoroughly providing information to the local inhabitants. For instance, if any public pathway is obstructed, the committee asks the community to clean-up to preserve the nice landscape. The operation is requirement for cooperation, rather than legal enforcement. The official announcement reaching the whole community oftentimes attains the local cooperation.

\subsection{Chanthaboon Waterfront Community}

After the conflagration in 1990, many houses were damaged. Some inhabitants settled down in the neighboring areas. Chanthaboon Waterfront Community was deteriorated and changed from a commercial area to a residential area. According to the census in $1979,50 \%$ of inhabitants were building owners. Another $50 \%$ were lessees and majority of them were old people. Some buildings without residents were abandoned. However, some original architecture and way of life which reflect the historical value from past to present, still persisted.

During 2009-2011, the community was restored by the locals, Office of Commercial Affairs Chanthaburi and Arsomsilp Institute of the Arts. The "Chanthaboon riverside community" volunteer group conducted the community activities under the vision "Culture before commercial." Forty-six buildings worth preservation were studied and seriously preserved. The house No. 69 was renovated to be a community learning house where historical, cultural and traditional exhibitions were displayed. When the community became well-known, it attracted more tourists. (Boonyakan and SuchaXaya, 2015:61) The restoration and preservation plan of Chanthaboon Waterfront Community with local participation was initiated in line with development policy of local agencies.Eventually, the plan gained recognition from the local inhabitants. (Boonyakan and SuchaXaya, 2015:63)

The community drafted the public space improvement plan and supervision measure which were resolved based on the local consensus. Although the plan and measure were not implemented by the community, it was a good sign. The community and municipality paid attention to the plan and realized the necessity of community preservation plan. However, it takes a long-term operation to seriously carry out the community restoration and preservation. (Boonyakan \& SuchaXaya, 2015:80)

From the in-depth interview, the participation process here means enhancement of the target group's participation, from the level of information and opinion provision to the decision-making. This leads to the community's mutual acceptance, and consequently, the systematically-planned transformation in the community. The community's representatives use the local cable media to declare the community's standpoint. Some inhabitants renovate their buildings in line with the design guideline. It proves that the process can boost the local understanding and awareness of community restoration and preservation.

As for the factors supporting the local participation, the first factor is the architect who presents the important information which stimulates the community's opinion expression and learning process. It leads to the mutual thinking and decision-making in the community. The second factor is group conversation. It is a method which allows the broad participation, under which the inhabitants can fully express their opinions. As a result, they can mutually find the resolution and pursue the solution by themselves through the public forum. 


\section{Discussion}

With regard to the historic community preservation in Thailand according to the case studies with following characteristics; (1) the community has managed the preservation in the locality for some time, (2) there is a local group working under the purpose of community preservation. (3) The preservation activities have been continuously carried out. (4) Such preservation activities can conserve buildings and physical environment to the extent that some outstanding features of buildings and environment still exist. (5) Original inhabitants in the community preserve their unique way of life and culture, the main factor of the successful preservation is the local participation in the preservation process. The academic organizations such as universities or institutions provide the consultation regarding the preservation principles and operational methods. The governmental agencies provide advices, budget and legal support.

The historic community preservation is gradually implemented. It is not necessary to operate the preservation of the entire area at the same time. It can start from a small area or even one building, so that the locals slowly realize the benefits and advantages of preservation. Afterwards, the locals naturally want to participate in the preservation by themselves. Consequently, the preservation can sustainably continue by the participation of inhabitants in the community in the long term. This method is suitable to Thai context where the government cannot fully support the preservation.

The tourism should not destroy the cultural heritage. One way to sustain the community is the concept of sustainable tourism. It aims to maintain the balance between the tourism development which contributes to the economic growth and cultural heritage preservation. This concept is based on the definition of sustainable cultural tourism, i.e. the tourism which boosts the economy, but does not destroy the tourism resources. It should not ruin the cultural values of the tourist sites and social structure of that area.

There are two factors which can help reduce the negative impact of tourism. The first factor is the local administration with authority to manage and administrate the area. The administration unit must have authority to announce regulations for physical control and tax measures, which are the structural control.

The second factor is the local inhabitants. They are the main drive for the better change. The community's participation and its strength are significant. The learning from other strong communities with regard to tourism management can serve as a direction for sustainable tourism management in another community (Pongsakornrungsilp. 2014). The samples of local groups participating in cultural heritage preservation include, the Maehongson Old House Club, Songkhla Heritage Society, Sam Chuk Market Development Committee, etc. (Chukaew, 2014) These groups are volunteer locals cooperating with the governmental sector, communities, and the ally networks to achieve community restoration through local participation. Moreover, the participation through the consultation, such as "close discussion" is adopted in line with the Thai context. The consultation through group interaction in the form of group conversation is adopted in many areas. With this method, the preservation plan is more recognized in the communities.

At last, this research found an important conclusion that the suitable historic community preservation in Thailand should have approval and collaboration from local people and this local people should improve their cooperation and participation. Therefore, these research findings could assist designers, planners or people involved in historical community preservation works and activities in Thailand for appropriateness and efficiency.

\section{Acknowledgments}

I am heartily thankful to my advisor, Panayu Chairatananonda, whose encouragement, guidance and support from the initial to the final level enabled me to develop an understanding of the subject. Lastly, I offer my regards and blessings to all of those who supported me in any respect during the completion of the project.

\section{References}

Boonyakan, K., \& SuchaXaya, C. (2015). Kan Chattham Naeothang Anurak Lae Fuenfu Chumchon Dangdoem Duai Krabuankan Mi Suanruam Korani Sueksa Chumchon Rim Nam Chanthaboon [Conservation and Revitalization Guidelines for Traditional Communities by Participatory Approach: Chanthaboon Waterfront Community Case Study]. Academic Journal: Faculty of Architecture, Khon Kaen University (Vol. 14, No. 1, pp. 59-82). Khon Kaen: Khon Kaen University.

Chantavanich, S. (2016). Withikan Wichai Choeng Khunnaphap [Qualitative Research]. Bangkok: Chulalongkorn University.

Chukaew, P. (2014). Kan Anurak Chumchon Thiyuasai Dangdoem Khong Thai Prasopkan Chak Kan Thamngan Phak Sanam [The Conservation of Thailand's traditional residential communities: The Field Work 
Experience]. Bangkok: Pluspress.

Creswell, J. W. (2013). Qualitative Inquiry and Research Design: Choosing Among Five Approaches. Sage.

Denzin, N. K., \& Lincoln, Y. S. (1998). Strategies for Qualitative Inquiry. Thousand Oaks, Calif: Sage.

Feilden, B., \& Jokilehto, J. (1998). Management guidelines for World Cultural Heritage sites (2nd ed.). Rome: ICCROM.

Groat, L., \& Wang, D. (2002). Architectural Research Methods. New York: John Wiley \& Sons.

Kamolsakdavikul, S. (2013). Samchuk, The Retromarket: The Politics of Space and The Business of Nostalgia. Institute of Culture and Arts Journal: Srinakharinwirot University, 14(2), 67-77. Bangkok: Srinakharinwirot University.

Lapenas, D. (2002). Historic Preservation: Gentrification or Economic Development. Retrieved from http://www.skidmore.edu/ bturner/ED Student Web Files/dlapenas5.html

Miles, M. B., \& Huberman, A. M. (1994). Qualitative Data Analysis: A sourcebook. Beverly Hills: Sage Publications.

Pimolsathien, Y. (2013). Kan Prapprung Fuenfu Mueang Lae Kan Anurak Mueang [Conservation of urban and revival of urban]. Bangkok: Thammasat University.

Pimolsathein, Y. (2012). Critical Issues on The Conservation of Historic Urban Community For Thailand. Najua 9, 85-99. Bangkok: Silapakorn University.

Pongsakornrungsilp, P. (2014). The Management of Sustainable Community-Based Tourism: The Case of Ban Kokekrai, Phang Nga Province. Veridian E-Journal: International Humanities, Social Sciences and arts, 7(3), 650-665. Bangkok: Silapakorn University.

Prompayuk, S. \& Chairatananonda, P. (2017). The Emigrating of The Natives In The Central Region Community Of Thailand From The Tourism Adaptation. Environment-behavior Proceedings Journal Vol 2, No 5 (2017), pp. 263-268. http://dx.doi.org/10.21834/e-bpj.v2i5.617

Saepoo, S., Assawakowitwong, N., \& Jirawattawee, M. (2007). The area of Samchuk 100-Year Market: Community Mechanisms for Conservation. Bangkok: Chulalongkorn University Press.

Sahachaiseri, N. (2005). Research in Social Science and Behavioral Science in Urban Planning. Bangkok: King Mongkut's Institute of Technology Ladkrabang.

Seublah, K. (2013). Samchuk Wanni [Sam Chuk Today]. Samut Sakhon: Pimdee Co., Ltd.

Sudchaya, S. (2009). Kan Anurak Mueang [Urban Conservation]. Bangkok: Amarin printing and publishing.

Sukolratanametee, S. (2009). Historic Preservation in The United States of America. Journal of The Faculty of Archtecture King Mongkut's Institute of Technology Ladkrabang, 8(1), 1-9. Bangkok: King Mongkut's Institute of Technology Ladkrabang.

Tonubol, P. (2013). Khwam Pen Ma Lae Khwamsamkhan Khong Kan Anurak Sathapattayakam [History and Importance of Architectural Preservation]. Journal of Department of Public Works and Town \& Country Planning (No. 41, pp. 29-34). Bangkok: Department of Public Works and Town \& Country Planning.

United Nations. (2012). The future we want: Outcome document adopted. Rio +20 Conference on Sustainable Development. Rio de Janeiro meeting, June, 1-49.

\section{Copyrights}

Copyright for this article is retained by the author(s), with first publication rights granted to the journal.

This is an open-access article distributed under the terms and conditions of the Creative Commons Attribution license (http://creativecommons.org/licenses/by/4.0/). 